\title{
Repercussão da violência na mulher e suas formas de enfrentamento ${ }^{1}$
}

\author{
Ana Cláudia Wendt dos Santos ${ }^{2}$ \\ Carmen Leontina Ojeda Ocampo Moré \\ Universidade Federal de Santa Catarina, Florianópolis-SC, Brasil
}

\begin{abstract}
Resumo: A violência contra a mulher é um tema complexo pela multideterminação de elementos de análises que nela convergem. Esta pesquisa objetivou caracterizar a repercussão da violência na mulher e suas formas de enfrentamento. O estudo foi exploratório-descritivo e adotou a metodologia qualitativa, sendo as participantes 10 mulheres agredidas que prestaram queixa em uma Delegacia da Mulher. A coleta de dados realizou-se por meio de entrevista semiestruturada, e para a análise dos dados utilizaram-se o software Atlas/ti 5.0 e a Teoria Fundamentada Empiricamente. Identificou-se a repercussão da violência na mulher por meio da insônia, da instabilidade emocional, da ideação suicida, do isolamento social e das estratégias de enfrentamento que foram focados no diálogo com amigos, familiares e colegas de trabalho; na busca de encontros sociais e no uso de medidas, tais como: tentativa de separação, saída de casa e denúncia. Considera-se que os dados obtidos subsidiam e qualificam intervenções e o atendimento de mulheres agredidas.
\end{abstract}

Palavras-chave: mulheres espancadas, violência, enfrentamento.

\section{Impact of violence on women and their ways of coping}

\begin{abstract}
Violence against women is a complex issue by the multiplicity of elements of analysis that converge on it. This study aimed to characterize the impact of violence on women and their ways of coping. The study was exploratory and descriptive, and adopted a qualitative methodology, the participants were 10 battered women, filed a complaint in a Police Office for Women. Data collection took place through semi-structured interviews and data analysis used the software Atlas / ti 5.0 and Grounded Theory. We identified the impact of violence on women by insomnia, emotional instability, suicidal ideation and social isolation and coping strategies that were focused on dialogue with friends, family and coworkers, in search for social gatherings and the use of measures, such as attempted separation, leaving home and denunciation. It is considered that the data obtained subsidize and qualify interventions and care of abused women.
\end{abstract}

Keywords: battered females, violence, coping behavior.

\section{Repercusión de la violencia sobre mujeres y estrategias de enfrentamiento}

Resumen: La violencia contra la mujer se caracteriza por su complexidad y multiplicidad de elementos de análisis que convergen. Este estudio buscó caracterizar el impacto de la violencia sobre la mujer y sus estrategias de enfrentamiento. Fue una investigación cualitativa, siendo las participantes 10 mujeres que hicieron denuncia por agresión en Comisaría de Mujeres. La recopilación de los datos fue realizada a través de entrevistas semi-estructuradas, y para el análisis fue utilizado el sofware Atlas/ti 5.0 y la Grounded Theory. Fueron identificados como indicadores del impacto de la violencia: falta de sueño y de apetito, inestabilidad emocional, ideas suicidas y aislamiento social. Las formas de enfrentamiento tuvieron como base: los diálogos con amigos, familiares, compañeros de trabajo, encuentros sociales y uso de actitudes como: tentativa de separación, salir del hogar y denuncia. Se considera que los datos obtenidos auxilian para calificar la intervención profesional y la atención de las mujeres maltratadas.

Palabras clave: mujeres maltratadas, violencia, enfrentamiento.

É consenso, na literatura pesquisada (Cantera, 2007; Santos \& Izumino, 2005), a multideterminação da violência exercida contra a mulher, no sentido tanto da diversidade de elementos de análise que nela convergem como em termos da diversidade de conceituações utilizada para nomear a violência contra a mulher e a posição adotada pela mesma, seja em termos de vítima ou de cúmplice.

\footnotetext{
${ }^{1}$ Este texto foi revisado seguindo o Acordo Ortográfico da Língua Portuguesa (1990), em vigor a partir de $1^{\circ}$ de janeiro de 2009. Agradecemos à CAPES pelo apoio financeiro que nos possibilitou a realização deste estudo.

${ }^{2}$ Endereço para correspondência:

Ana Cláudia Wendt dos Santos. Rua José Batista Rosa, 432. CEP 88.036-
}

150. Florianópolis-SC, Brasil.E-mail: aclws@ig.com.br
No campo do conhecimento sobre este tema, verifica-se a presença de correntes teóricas advindas de estudos feministas que, ora analisam a mulher como vítima e cúmplice da situação de agressão, ora exclusivamente como cúmplice, sendo estas controvérsias problematizadas mais profundamente a partir da década de 1990 (Cantera, 2007; Santos \& Izumino, 2005).

Considera-se que, ao pensar a mulher em situação de violência, se está falando de um processo interacional que não pode ser concebido como uma construção individual, mas sim como uma trama relacional na qual todas as partes envolvidas se afetam recursivamente. Ou seja, nas relações conjugais, familiares e sociais, as ações entre seus integrantes tanto podem gerar violência como podem gerar condições de submissão à mesma. Assim, a fronteira entre 
agressor e agredido, entre vítima e cúmplice é de difícil demarcação quando se concebem as situações de violência inseridas em um processo de construção relacional, pois todos os envolvidos, ao assumir determinadas posições, podem se colocar como vítimas ou cúmplices das mesmas. A tomada de posição, produto desse processo de construção, dependerá diretamente do contexto em que a situação de agressão ocorrer.

Assim, no presente estudo, quando se utiliza o termo vítima e agressor, se está evidenciando a situação das mulheres quando recorrem aos dispositivos legais de suporte psicossocial e de proteção aos direitos da mulher, ou seja, está se referindo à posição que as mulheres agredidas assumem, assim como de quem as agride, frente às políticas públicas editadas pelo governo federal para proteção da mulher e prevenção da violência contra a mesma, e às instituições de referência que visam a prestar o devido atendimento a estas mulheres, como as Delegacias Especializadas.

Especificamente, a violência física perpetrada pelo próprio marido/companheiro ou por algum membro da família (pai, irmão) é considerada a principal configuração que a violência assume quando é praticada contra a mulher. Observa-se, aqui, que o uso do poder dos homens sobre as mulheres encontra-se na base da violência que é exercida contra elas e ocorre como um modo de dominá-las e controlá-las, especialmente se ela for sua parceira em uma relação conjugal (Azevedo, 1985; Carneiro \& Oliveira, 2008; Cavalcanti, Gomes, \& Minayo, 2006; Ministério da Saúde, 2002).

Nessa direção, cabe destacar os estudos sobre a influência das diferenças de gênero, enquanto desigualdades histórica e socialmente construídas entre homens e mulheres, e que ainda hoje é um dos elementos fundamentais para compreender a complexidade do fenômeno da violência exercida contra a mulher. Existem certos fatores que servem de base para a ocorrência das desigualdades entre os gêneros e para a sua perpetuação. Entre esses, estudos como os de Alberdi (2005), Azevedo (1985) e Cantera (2007) apontam para o machismo como um dos componentes que fazem parte da nossa sociedade, o que contribui para a compreensão de que o homem é essencialmente mais forte e mais competente do que a mulher, não apenas fisicamente, mas também psicologicamente mais bem preparado do que a mesma, ideologia esta que serve para naturalizar uma situação que é socialmente construída.

Além do machismo, existe o patriarcado, entendido como um modo de organização sociocultural que estrutura as relações sociais e a divisão de papéis entre homens e mulheres e que legitima o homem como o único chefe da família (Alberdi, 2005; Azevedo, 1985; Cantera, 2007). Apesar de estar paulatinamente desaparecendo, o patriarcado ainda serve para alimentar as desigualdades entre os gêneros, pois como afirma Alberdi (2005) "o uso da força como método para a resolução de conflitos se legitima quando exercem os homens em um modelo social que se apoia na supremacia masculina" (p. 23, tradução nossa).
Associada ao machismo e ao patriarcado existe a educação diferenciada que ainda é oferecida às crianças. Desde a mais tenra idade, elas aprendem o que é ser homem e o que é ser mulher (o modo de se vestir e se comportar; que sentimentos devem ou não devem expressar), ou seja, é no processo de desenvolvimento psicossocial que os sujeitos estabelecem as bases para agir de acordo com as diferenças de gênero (Alberdi, 2005; Azevedo, 1985).

Nesse sentido, a discussão de gênero, que vai além das diferenças sexuais, torna-se necessária para melhor compreender os efeitos da violência contra a mulher, principalmente em termos das reações comportamentais, emocionais e sociais das mesmas, as quais por muito tempo ficaram subjugadas a preconceitos e incompreensões, impedindo de aprofundar e explorar as estratégias de enfrentamento por elas utilizadas.

Embora as estatísticas da violência contra a mulher sejam alarmantes e apesar de ter aumentado o número de denúncias, principalmente em decorrência da aplicação e divulgação da Lei No. 11.340/06 (2006) (conhecida como Lei Maria da Penha), que facilitou a proteção das mulheres para realizarem a denúncia e também o atendimento ao agressor, dificilmente é possível obter o número real de mulheres que são agredidas diariamente. Tal fato ocorre, justamente, porque muitas mulheres são agredidas dentro das próprias casas, começando pelo pai, pelo irmão e, posteriormente, pelo marido/companheiro (Bedone \& Faúndes, 2007; Carneiro \& Oliveira 2008; Villela \& Lago, 2007). Em função disso, as mulheres se calam, uma vez que temem que um ato violento ainda mais grave seja cometido contra elas, pois a probabilidade de sofrer uma agressão ainda maior do parceiro, incluindo o homicídio, aumenta significativamente, depois que a mulher decide abandonar a relação conjugal (Ferrari \& Vecina, 2002).

Mulheres agredidas dentro da própria família igualmente tendem a minimizar o problema, desejando acreditar que o marido/companheiro, pai ou irmão não é tão violento como parece. Elas também sentem vergonha, culpa e baixa autoestima por viverem esse tipo de situação, além do medo de ficarem sozinhas (Bedone \& Faúndes, 2007; Villela \& Lago, 2007).

Outro aspecto que deve ser considerado diz respeito à condição social e econômica das mulheres, ou seja, muitas delas ainda recebem menores salários do que os homens, apesar de realizarem a mesma função que os mesmos (Azevedo, 1985). Elas também trabalham mais horas e muitas vezes em atividades não remuneradas, como é o caso dos afazeres domésticos. Depender economicamente do marido/ companheiro, ou ganhar menos do que ele, serve para aumentar a fragilidade, a vulnerabilidade e a desvalorização na qual a mulher se encontra (Alberdi, 2005; Carneiro \& Oliveira, 2008).

Além disso, estudos (Alberdi, 2005; Schraiber e cols., 2007), que apresentam dados a respeito do grau de instrução de mulheres que são agredidas, evidenciam que normalmente 
elas possuem o ensino fundamental ou médio, o que limita as possibilidades de escolha profissional das mesmas, além de fazer com que optem por profissões pouco valorizadas socialmente e de baixa remuneração. Tal situação igualmente converge na direção de manter a mulher dependente dos homens e/ou na condição de subalterna a eles.

Somados a esses fatores, outros também listados pelas pesquisas (Ministério da Saúde, 2002; Silva, Coelho, \& Caponi, 2007) como possíveis motivos para as mulheres continuarem em uma relação onde há violência são: (a) história familiar onde havia agressão entre os pais ou pessoas próximas a ela, o que propicia com que repita esse modelo na sua própria relação conjugal; (b) crença na mudança de atitude do marido/companheiro; (c) crença na incapacidade de viver sem o marido/companheiro e sem um pai para os filhos; (d) medo de que, com a separação, perca a guarda dos filhos ou tenha de sair de casa; entre outros. Vale acrescentar, ainda, que pesquisas (Peralta \& Fleming, 2003; Wenzel, Monson, \& Johnson, 2004) verificaram que muitas mulheres passaram a abusar do uso de bebida alcoólica e outras drogas como forma de suportar as agressões sofridas.

\section{Estratégias de enfrentamento}

De acordo com os cognitivistas Folkman, Lazarus, Gruen e DeLongis (1986), estratégias de enfrentamento podem ser explicadas como o empenho cognitivo e comportamental que uma pessoa exerce, para tentar reduzir ou controlar as demandas advindas de mudanças ocorridas no contexto em que se encontra e que o sujeito experimenta como excedendo seus recursos pessoais para suportá-las.

Segundo Folkman e cols. (1986), as estratégias de enfrentamento têm funções distintas, a saber: (a) estratégia de enfrentamento focada no problema - esforço centrado na modificação da situação provocadora de estresse, por meio do pedido de ajuda aos outros, da disposição em sair à procura de informações e da realização de ações que objetivam a solução dos problemas e que possam gerar satisfação a si mesmo; (b) estratégias de enfrentamento focadas na emoção - energia direcionada à regulação da emoção vinculada à situação estressante, com o intuito de modificar o estado emocional gerado, o que pode ser feito com o uso de tranquilizantes, do fumar, ou da realização de alguma atividade física, para citar alguns exemplos.

No cotidiano dos indivíduos, os comportamentos aprendidos e que se tornaram habituais são os recursos que primeiramente os mesmos utilizam para enfrentar as situações estressoras. Entretanto, novas estratégias de enfrentamento podem ser aprendidas, bem como podem ser usadas e descartadas, o que significa que uma pessoa pode se desfazer dos recursos que utilizava para trocar por outros mais eficazes no enfrentamento de seu problema (Antoniazzi, Dell'Aglio, \& Bandeira, 1998).

Folkman e cols. (1986) destacam, ainda, que a escolha das estratégias de enfrentamento está estreitamente relacionada às características psicológicas do indivíduo, às suas crenças e aos seus valores culturais/existenciais. Por sua vez, segundo os autores acima e Moré (2005), o auxílio que uma pessoa possui em termos de redes sociais de apoio e recursos materiais, entre outras variáveis, igualmente influencia no modo como ela avalia uma situação como estressora ou não, bem como na escolha das ferramentas que irá utilizar para lidar com tal situação.

Mulheres que são agredidas frequentemente fazem uso de estratégias de enfrentamento, ou para poderem sobreviver à relação violenta a que são submetidas dentro da família, ou como forma de conseguir superar tal ocorrência. Assim, tendo esse horizonte de compreensão, o presente trabalho objetivou caracterizar a repercussão da violência na mulher e suas formas de enfrentamento, na perspectiva de mulheres que foram agredidas. Entende-se que a relevância deste estudo está em somar dados a essa temática atual, visando a aprofundar o conhecimento das experiências de mulheres em situação de violência, para com isso poder sustentar ações de efetivo apoio social, seja por meio de intervenção profissional, seja subsidiando a implementação das políticas públicas relacionadas à saúde, à segurança e aos aspectos psicossociais das mulheres.

\section{Método}

A presente pesquisa adotou os pressupostos da metodologia qualitativa, caracterizando-se também por ser exploratório-descritiva, pois procurou descrever, caracterizar e relacionar aspectos das situações vividas pelas participantes deste estudo.

\section{Participantes}

As participantes foram 10 mulheres que apresentaram queixa em uma Delegacia Especializada de Atendimento à Mulher localizada na região do Sul do Brasil, sendo esse número definido a partir da saturação dos dados. Ou seja, a partir da sexta e sétima entrevistas, começaram a ser observadas regularidades temáticas frente aos objetivos propostos. No entanto, dada a complexidade do assunto, se optou por continuar convidando outras mulheres, no intuito de obter dados que aportassem outros significados. Assim, o número final de 10 participantes se configurou a partir da constatação da recorrência temática, e de que poucos dados diferenciais surgiram acerca do objetivo geral deste estudo.

Os critérios utilizados na seleção das entrevistadas foram: (a) ser maior de 18 anos; (b) a situação de violência ter ocorrido um mês antes do contato com a pesquisadora, para evitar expor as mulheres a um maior abalo produzido pela situação de violência, e por entender que o impacto inicial da denúncia e suas consequências teriam diminuído, dando condições para elas realizarem as entrevistas; (c) apresentar condições de compreender os objetivos da pesquisa e de estabelecer uma comunicação razoavelmente clara com 
a entrevistadora, o que pôde ser verificado no contato via telefone com as participantes, quando se explicou sobre o que tratava o estudo e foi feito o convite para elas participarem do mesmo, e, posteriormente, durante a realização das entrevistas.

\section{Instrumento}

Para a coleta de dados, foi utilizada a entrevista semiestruturada, composta por um roteiro de perguntas elaboradas em função dos objetivos da pesquisa. Trata-se de uma ferramenta importante para contextualizar o comportamento das participantes, pois fez emergir seus sentimentos, atitudes, motivos, intenções e valores (Biasoli-Alves, 1998).

\section{Procedimento}

\section{Coleta de dados}

A coleta de dados iniciou-se com o acesso aos Boletins de Ocorrência e Termos Circunstanciados realizados naquela instituição durante o ano de 2008, visando a fazer a triagem dos nomes e números de telefone das mulheres que atendessem aos critérios de inclusão estabelecidos. Em seguida, iniciou-se o contato via telefone, convidando-as a participar em horário e local por elas indicados. Foi sugerido o Serviço de Atenção Psicológica (SAPSI) da Instituição Educacional de referência da pesquisadora como um possível lugar para o encontro, no intuito de que o ambiente fosse o mais tranquilo e seguro para as mesmas.

De 40 mulheres convidadas, 10 aceitaram realizar a entrevista, sendo que sete solicitaram que o encontro ocorresse na casa delas, e três pediram para que fosse realizado no SAPSI. A entrevista começava após a explicitação, autorização e assinatura do Termo de Consentimento Livre e Esclarecido. As entrevistas foram gravadas e transcritas na íntegra para posterior análise, sendo os nomes das participantes substituídos por nomes fictícios.

\section{Análise dos dados}

Para a análise dos dados, foi utilizada a Grounded Theory (Teoria Fundamentada Empiricamente) de Strauss e Corbin (2008), onde a coleta de dados, análise e eventual teoria mantêm uma relação muito próxima entre si, sendo esta última derivada dos dados sistematicamente reunidos e analisados por meio da pesquisa. O processo de análise envolveu as seguintes etapas: (a) interação com os dados, realizado à medida que eles foram coletados e que se desenhavam à luz do objetivo da pesquisa, por meio de leituras sucessivas do material textual das entrevistas, promovendo uma análise em profundidade e possibilitando a ampliação da compreensão do significado das experiências descritas pelas participantes; (b) os dados foram, então, desmembrados, examinados e comparados, possibilitando a elaboração de categorias de acordo com suas especificidades; (c) as categorias foram nomeadas a partir da emergência de pontos nucleares que foram se mantendo na diversidade e complexidade dos dados, procurando chegar à representação dos significados dos códigos agrupados; (d) a partir das categorias principais, relacionaram-se subcategorias e seus respectivos elementos de análise, os quais auxiliaram na descrição, compreensão e sustentação das categorias principais; (e) os dados obtidos, a partir das entrevistas e da literatura apresentada, sustentaram a nomeação das categorias que, tomadas em seu conjunto, apoiaram uma compreensão integrada da categoria principal e/ou fenômeno central deste artigo, que é a repercussão da violência na mulher e as estratégias de enfrentamento utilizadas pelas mesmas.

Nesse sentido e para responder à categoria principal, delinearam-se, a partir dos dados obtidos, quatro categorias de análise: (a) agressão como situação-limite; (b) reações comportamentais e emocionais diversas; (c) sentimentos da mulher em relação ao agressor; (d) estratégias de enfrentamento: bem-sucedidas e malsucedidas.

Para auxiliar nesse processo de análise dos dados, foi utilizado o software Atlas/ti 5.0, que se trata de um programa de análise de dados qualitativos, útil para a organização de grande quantidade de textos, gráficos, informações de áudio ou vídeo, além de ajudar a estabelecer relações e a construir categorias (Muhr, 2004).

\section{Considerações éticas}

Este estudo foi submetido à aprovação no Comitê de Ética e Pesquisa com Seres Humanos da Universidade Federal (Parecer Consubstanciado Projeto n ${ }^{\circ}$ 393/2007), bem como por todos os níveis decisórios da Delegacia Especializada de Atendimento à Mulher.

\section{Resultados e Discussão}

O conjunto de categorias de análise nucleado em torno do objetivo do presente artigo, o qual se constitui, na perspectiva de Corbin e Strauss (2008), na categoria principal deste estudo, tentou trazer à tona dados a respeito de uma temática que, por consenso na literatura pesquisada e desde os diferentes campos de conhecimentos, se caracteriza por ser complexa e multideterminada pela diversidade de elementos que convergem e que se afetam mutuamente em sua análise.

Nesse sentido, cabe destacar, em um primeiro momento, certas características evidenciadas pelo conjunto das entrevistas e que auxiliaram a melhor contextualizar o objetivo proposto.

A maior parte das mulheres entrevistadas encontrava-se na faixa etária entre os 30 e 40 anos, ou seja, na fase do auge de sua produtividade profissional; cinco participantes declararam-se solteiras (embora vivessem junto com seus parceiros) e três declararam que viviam em regime de união estável com seus companheiros. Apenas uma delas declarou-se casada e 
outra, separada, mostrando o predomínio de relações não oficiais entre as participantes.

Quanto ao grau de escolaridade, houve o predomínio de mulheres que possuíam o ensino fundamental incompleto e o ensino fundamental completo. As principais ocupações citadas por elas foram as de doméstica e do lar, sendo que algumas se encontravam desempregadas. Em conformidade com o grau de escolaridade e o tipo de ocupação exercido, a maior parte da renda familiar declarada ficou entre um e dois salários mínimos mensais, demonstrando o contexto de necessidade/escassez em que essas mulheres viviam.

$\mathrm{O}$ agressor de nove das dez entrevistadas foi o próprio marido/companheiro. Vale destacar que duas dessas mulheres foram agredidas fisicamente tanto pelo companheiro, quanto pelo filho. Uma foi agredida exclusivamente pelo cunhado. A maioria das participantes tinha entre dois e cinco filhos.

Verifica-se, assim, que os homens se configuraram como os principais agressores das participantes deste estudo, sendo que todos pertenciam ao núcleo familiar das mesmas. No que diz respeito ao nível de escolaridade, destacou-se a baixa formação escolar, e a condição socioeconômica dessas mulheres mostrou-se precária, propiciando a dependência do marido/companheiro para poderem ter condições de vida para si mesmas e para os filhos. Dados que vão ao encontro dos estudos e pesquisas realizados por Azevedo (1985), Alberdi (2005), Bedone e Faúndes (2007), Cantera (2007), Carneiro e Oliveira (2008), Cavalcanti e cols. (2006), Ministério da Saúde (2002), Schraiber e cols. (2007), Villela e Lago (2007) e que revelam a trama relacional dessas mulheres, em que a relação familiar e conjugal constitui vínculo de risco potencial, diante das manifestações de violência, por um lado, e a necessidade de sobrevivência como condição de vida, por outro, deixaram em evidência um contexto que se sustenta pela presença de situações antagônicas.

\section{Agressão como situação-limite}

Esta categoria evidencia a situação de violência sofrida e a tomada de posição das mulheres frente à mesma. Dentre as atitudes tomadas pelos agressores e que foram consideradas intoleráveis pelas entrevistadas, motivando-as a procurar a Delegacia Especializada de Atendimento à Mulher, encontram-se, principalmente, as que dizem respeito à gravidade da agressão sofrida: "Ele (...) me deu um monte de soco na cabeça. Não, não pensei em outra coisa, fui direto pra Delegacia (...) dessa vez foi a gota" (Rosa); "Ele pegou o cabo de vassoura e me deu. Acertou aqui na testa (...) eu passei a mão, tinha sangue, eu disse: 'Ah, não, agora chega'. Aí peguei e chamei a polícia” (Magnólia).

A situação-limite, apontada pelas entrevistadas, colocou as mesmas diante do fato de que caberia a elas próprias tomar uma decisão acerca do que estava acontecendo na relação conjugal, e que, caso elas não tomassem nenhuma atitude para interromper o processo que estavam vivendo, a situação continuaria igual. Tal constatação parece estar diretamente relacionada à intensidade e à gravidade da violência padecida que tornaram as agressões intoleráveis e provocaram uma ação por parte delas, no intuito de mudar a história que, afinal, estavam ajudando a escrever.

Destaca-se, também, a questão da violência conjugal como um processo de agressões anteriormente recebidas no qual as entrevistadas estavam imersas e que, de certo modo, era naturalizado por elas, no sentido de não haver um movimento na direção de parar com o mesmo, além de revelar uma falta de atitude prévia frente a esta violência. Fato esse que remete ao estudo realizado por Schraiber e cols. (2007) que aponta que, embora as mulheres tenham admitido ter sido agredidas verbalmente e até fisicamente pelo marido/ companheiro, muitas delas não identificavam alguns destes atos como uma violência, mas como uma ação válida de ser utilizada no momento de resolver um conflito.

Além disso, conforme aponta a literatura sobre a violência contra a mulher (Bedone \& Faúndes, 2007; Ferrari \& Vecina, 2002; Ministério da Saúde, 2002; Silva e cols., 2007; Villela \& Lago, 2007), é possível inferir que, como essas mulheres foram agredidas dentro de casa, principalmente pelo marido/ companheiro, elas podem ter tentado acreditar que eles não eram tão violentos quanto parecia, ou podem ter se calado por medo de ficarem sozinhas, em condição financeira precária e sem um pai para os filhos, ou, ainda, por se sentirem culpadas ou envergonhadas por estar passando por tal situação. Os depoimentos apresentados na sequência apontam para algumas dessas direções, na medida em que mostram a tentativa de duas entrevistadas em destacar os pontos positivos de seus ex-companheiros, apesar da intensidade e da frequência das agressões verbais e físicas que sofriam deles: "Eu não posso reclamar, porque ele (ex-companheiro) me dava tudo que eu queria, assim. (...) Ele não era um monstro, assim, também, sabe?" (Rosa); "Eu não quero que ele (ex-companheiro) vá preso. (...) Ele não é drogado, ele não bebe, não fuma, não joga, não é nada disso, mas só que nunca se sabe, né? Perder ele... nem todo pai é que nem ele" (Violeta).

A agressão desferida pelo companheiro contra o filho também fez com que uma entrevistada decidisse por denunciar a violência provocada por ele. Entretanto, tal atitude não é o que se verifica entre mulheres que são agredidas por seus maridos/companheiros. Comumente o que ocorre é a tolerância tanto à violência sofrida quanto àquelas violências geradas contra os próprios filhos, inclusive quando se trata de violência sexual, para que se possa manter uma suposta e almejada unidade familiar, conforme verificado por Ferrari e Vecina (2002) e o que parece indicar o relato abaixo:

Ele [companheiro] voltou pra casa (...) a gente chegou num bom senso, porque a gente tava discutindo demais (...). Claro que quando ele ia visitar as criança, a neném pulava de alegria, a pequena. O menino (filho) até não sofreu tanto com a separação, mas a neném, toda vez que ela via o pai dela, ela ficava feliz da vida, entende? (Jasmim). 
O conjunto desses dados trouxe à tona um aspecto que permeou de modo transversal todas as narrativas das participantes que foram as diferenças de gênero, evidenciadas, principalmente, na obrigação de as mulheres aguentarem as agressões verbais e físicas que eram dirigidas a elas, seja por se considerarem incapazes de sobreviver sozinhas, seja para dar certa condição de vida para seus filhos, ou, ainda, pela cultura impregnada de que elas deveriam ceder para, com isto, evitar conflitos.

Isso ficou evidente na falta de compreensão por parte de algumas participantes do papel das mesmas na sustentação do ciclo da violência, pois ao procurarem desculpas para as atitudes tomadas pelos agressores ou ao tolerarem as agressões sofridas pelo cônjuge e seus familiares, apenas contribuíam para que as agressões verbais e físicas permanecessem mediando a relação entre eles (Alberdi, 2005; Azevedo, 1985; Cantera, 2007; Ferrari \& Vecina, 2002).

Nesse sentido, destaca-se a variedade de aspectos que, em termos de repercussão da violência, podem se articular e influenciar na tomada de decisão de uma mulher denunciar ou não as agressões sofridas, mostrando a complexidade e multideterminação em que se constitui o referido agravo (Cantera, 2007; Santos \& Izumino, 2005).

\section{Reações comportamentais e emocionais diversas}

Entre as reações comportamentais e emocionais padecidas pelas entrevistadas em função da violência sofrida, foram citadas a ocorrência de desânimo, dores de cabeça, insônia, angústia, ansiedade, choro frequente e instabilidade de humor. Além das reações descritas, elas também relataram terem sofrido repercussões físicas em função do abalo emocional com a situação vivida, como queda de cabelo, falta de apetite, perda acentuada de peso e o aparecimento de hematomas pelo corpo. Dados semelhantes podem ser encontrados nos resultados obtidos por pesquisas (Ferrari \& Vecina, 2002; Ministério da Saúde, 2002; Villela \& Lago, 2007) que igualmente relatam as diversas sequelas físicas e psicológicas que sofrem as mulheres que foram agredidas e que podem perdurar por meses e até anos, depois da situação de agressão ter ocorrido.

O uso de medicação psiquiátrica igualmente foi relatado por três participantes, sendo que duas utilizavam antidepressivos, e uma utilizava ansiolítico, fato este que difere das constatações feitas por Peralta e Fleming (2003) e Wenzel e cols., (2004) que apontam que, após sofrerem agressões frequentes, muitas mulheres se refugiaram no uso de bebidas alcoólicas e também começaram a usar drogas ilícitas. Somado a isso uma dessas entrevistadas afirmou ter pensado em se suicidar, e outra tentou alcançar tal objetivo, destacando-se, assim, o grau de prejuízo psicológico que a violência produziu nas participantes.

Outro dado relevante diz respeito a que quase todas as entrevistadas tiveram prejuízos em seus trabalhos em função das agressões sofridas, pois algumas passaram a ter dificuldades em se concentrar no mesmo, e outras perderam a vontade de trabalhar. O referido quadro vai ao encontro dos estudos (Ministério da Saúde, 2002) que apontam que mulheres agredidas têm prejuízos no serviço, pois perdem mais dias de trabalho e, devido ao sofrimento que a violência acarreta, acabam tendo de exercer suas atividades profissionais com maior esforço.

Além disso, mais uma repercussão comportamental e emocional a ser registrada diz respeito à saída do agressor de casa devido à denúncia realizada na Delegacia da $\mathrm{Mu}-$ lher. Os relatos destacaram a mudança no ambiente familiar, referindo-se especialmente à calma que pairou na residência, depois que o companheiro saiu de casa. Já outras entrevistadas expressaram alívio por não terem mais que prestar contas de suas rotinas de vida ao marido/companheiro, sendo que uma delas relatou ter tido a sensação de finalmente ter conquistado a "liberdade e felicidade" que sempre almejou, e outra de "ter vivido nos céus".

Tais situações parecem demonstrar que a repercussão da saída do agressor de casa foi tão satisfatória para as entrevistadas, que seria impossível para elas aceitá-los de volta. Contudo, nem todas as participantes conseguiram suportar a separação do companheiro. Para uma delas, a saída do agressor de casa foi vivida com pavor, em função de ele ter levado os filhos consigo. Portanto, quando ele pediu para voltar para casa, a solicitação foi prontamente atendida por ela. Nessa direção, outra participante, ao ver-se sozinha com os filhos, aceitou novamente o agressor em casa.

Desse modo, considera-se que as reações diante da separação do agressor mostraram o peso das tramas relacionais em que se gestam os ciclos de violência, deixando a mulher em condições muito difíceis de sustentar determinadas posições tomadas, em função das repercussões que tais posições podem gerar como: a perda dos filhos; ou o medo de acabar ficando sozinha, ou de ter de sair de casa; ou mesmo alimentar a crença de que não tem a capacidade de viver sem estar ao lado de um homem, como já apontado anteriormente e por outras pesquisas sobre o assunto (Azevedo, 1985; Bedone \& Faúndes, 2007; Ministério da Saúde, 2002; Silva e cols., 2007; Villela \& Lago, 2007).

Desse modo, foi possível verificar, no presente estudo, o conjunto de danos causados pela violência perpetrada contra as participantes, tanto em termos físicos e psicológicos (perda de peso, insônia, ideação suicida), como sobre o ambiente profissional (perda de concentração no trabalho), além das consequências geradas sobre o convívio familiar (falta dos filhos) e para a vida social das mesmas (falta de vontade de sair, de se arrumar).

\section{Sentimentos da mulher em relação ao agressor}

Quanto aos sentimentos das entrevistadas em relação aos agressores, percebeu-se a presença da ira e do desejo de vingança. Nesse caso é interessante observar que uma das participantes, embora esboçando o desejo de que o agressor 
"pagasse pelo que fez" (Dália), não se colocou como uma possível agente dessa vingança, nem mesmo em hipótese. Ela queria que, de algum modo, "algo acontecesse com ele" (Dália) e que o fizesse expiar pelo seu comportamento, como se não estivesse nas mãos dela providenciar, por exemplo, meios legais e jurídicos para que isto se concretizasse.

Por outro lado, quando houve a presença de carinho e cuidado por parte do agressor, mas com demonstrações de ciúmes, a reação da entrevistada foi de compaixão, afinal tratava-se do pai de seus filhos, assim como houve sentimento de mágoa. Nesses casos, a paternidade parece ter assumido um peso maior do que o fato de terem sido agredidas, destacando-se, ainda, o peso do valor da família para estas mulheres, elevado acima da ocorrência da violência em si.

Observa-se, novamente, aqui a presença de sentimentos contraditórios e ambivalentes, que se presentificaram na tomada de decisões frente a situações de violência e que, muitas vezes, impedem a mulher de perceber com maior clareza sua posição de sujeito na relação conjugal, ou seja, com capacidade e direitos de determinar os rumos do envolvimento com o marido/companheiro, e não apenas daquela que precisa se submeter às decisões e motivações arbitrárias do mesmo, como ocorre nas relações entre homens e mulheres em que as diferenças de gênero se traduzem por desigualdades de gênero, isto é, onde se intui que cabe exclusivamente ao homem definir e dirigir o caminho que será trilhado por ambos (Alberdi, 2005; Azevedo, 1985; Cantera, 2007).

\section{As estratégias de enfrentamento: bem-sucedidas e malsucedidas}

Em termos da repercussão da violência nas mulheres entrevistadas para este estudo, esta categoria congregou a totalidade de ações realizadas pelas participantes para lidar com as agressões padecidas.

Das estratégias de enfrentamento utilizadas pelas entrevistadas e que foram bem-sucedidas, destacou-se: buscar outras pessoas para conversar, como colegas de trabalho, amigos, vizinhos e familiares, assim como profissionais da psicologia e do serviço social e doutrinadores de uma determinada religião. As participantes da pesquisa se dispuseram a procurar pessoas que as ajudassem a diminuir o estresse e o sofrimento provocados pelas agressões sofridas e que contribuíssem para elas encontrarem uma solução para o problema enfrentado. Com isso, identificou-se que utilizaram o que se denomina de estratégias de enfrentamento focadas na emoção e no problema, conforme encontrado na literatura pesquisada sobre o assunto (Antoniazzi e cols., 1998; Folkman e cols., 1986).

A rotina absorvida no trabalho, mesmo que fosse o serviço da casa, também foi uma estratégia bastante utilizada por elas, pois contribuía para que o pensamento não ficasse retido na situação: "Trabalho muito, faz esquecer" (Magnólia). Já nas horas em que elas não podiam fazer uso do trabalho, outras estratégias foram postas em prática, como sair para visitar os parentes, sair com as amigas, passear no shopping e, até mesmo, sair para correr. Assim, verificou-se que um dos principais objetivos buscados pelas entrevistadas com essas ações foi o de tentar desviar o foco do que aconteceu e que as estava atormentando no momento, o que indica, conforme Folkman e cols. (1986), o uso de estratégias de enfrentamento voltadas a conseguir lidar com a repercussão que a situação de violência lhes provocava.

Elas igualmente demonstraram as condições que tinham para enfrentar as consequências da violência, quando se dispunham a resolver questões práticas como pagar dívidas, planejar as despesas mensais e mudar de residência sem a ajuda do marido/companheiro.

Além disso, os depoimentos obtidos indicaram que tanto os traços de personalidade das entrevistadas quanto as variáveis do contexto a sua volta possibilitaram a elas tentar superar a situação ocorrida, ou seja, ter disposição de "ir atrás" de soluções, de ser "batalhadora" e "alegre", ter um emprego que dava condições financeiras a algumas delas de "pagar suas contas", bem como ter amigos que lhes serviram de suporte. Ou seja, foram elementos que, em conjunto, se constituíram em meios para darem outro rumo à própria vida, aspecto igualmente ressaltado por autores como Antoniazzi e cols. (1998) e Folkman e cols. (1986).

O medo de sofrer novas agressões também fez com que duas participantes apelassem para o uso de recursos de enfrentamento mais drásticos e que ainda não haviam sido utilizados por elas, como passar a dormir com uma marreta ao lado da cama, andar com spray de pimenta na bolsa e usar a intimidação para enfrentar os agressores. Nesse sentido, Antoniazzi e cols. (1998) destacam que o uso de novas estratégias de enfrentamento normalmente é realizado, quando outras que foram aprendidas e anteriormente postas em prática não alcançaram o efeito almejado. As antigas estratégias, então, são descartadas, e outras compreendidas como mais eficazes são colocadas em ação, como ocorreu nas situações mencionadas acima.

Em termos de estratégias de enfrentamento que foram malsucedidas, pode-se citar o caso da entrevistada que tentou, por meio da busca de um emprego, melhorar a relação estabelecida com o companheiro. Entretanto, o fato de ter ido à procura de um trabalho foi justamente o que acabou provocando a agressão física mais severa do companheiro contra ela e que a fez ir atrás da ajuda da polícia.

Nessa mesma linha do enfrentamento malsucedido, está a tentativa de uma participante de se separar e impor limites ao companheiro, pois acreditava que tais atitudes modificariam a situação estressante vivida. No entanto, tais iniciativas resultaram em insucesso para a entrevistada em questão, já que ela voltou a ser agredida fisicamente e verbalmente por ele.

Apesar das dificuldades enfrentadas e que possivelmente continuariam a enfrentar, algumas participantes planejavam um novo projeto de vida, principalmente acerca da chance de finalmente conseguir um emprego, ou de arranjar 
um novo, mas em outro estado do país. Para uma das entrevistadas, a possibilidade que ela vislumbrava referia-se ao elevar seu grau de instrução e, com isso, ascender a um novo tipo de trabalho, enquanto para outra, a oportunidade de poder viver com segurança e liberdade com suas filhas seria o suficiente para tornar sua vida melhor.

Acredita-se que as estratégias de enfrentamento da violência evidenciadas nas mulheres participantes deste estudo, sejam elas bem ou malsucedidas, ressaltaram singularidades e possibilidades de resolução do conflito, ainda que de modo temporário, o que requer uma análise mais aprofundada das redes de apoio as quais elas recorreram, pois se avalia que ali pode estar uma fonte de suporte efetivo para cortar o circuito de violência dentro da família e contra a mulher. Considerase, também, que as redes de suporte psicossocial têm uma importância essencial no processo de conscientização do papel da mulher, por meio de recursos humanos sensibilizados e capacitados para o investimento em programas de educação para cidadania e saúde (Moré, 2005).

\section{Considerações finais}

Entende-se que os dados deste estudo precisam ser contextualizados e compreendidos no universo da pesquisa qualitativa. Assim, a representatividade da amostra não foi o âmago da investigação, mas sim a imersão nos significados e sentidos das experiências de um grupo de mulheres que se dispuseram a participar espontaneamente, sendo este um dado relevante, na medida em que houve dificuldade de acesso às mesmas no processo da coleta de dados.

No que diz respeito ao objetivo deste artigo, a repercussão da violência na mulher e as estratégias de enfrentamento utilizadas por elas passam necessariamente pelo reconhecimento das questões de gênero e dos contextos socioculturais que, de forma transversal, impregnaram os significados, as posturas adotadas e as formas de expressão da violência contra a mulher e que têm relação direta com o sucesso ou não das estratégias utilizadas, cabendo às redes pessoais ou sociais um papel importante na ruptura do circuito da violência.

Por sua vez, a repercussão da violência na mulher e as estratégias de enfrentamento utilizadas, também, envolvem o conhecimento da presença de posturas ambivalentes por parte da mulher, seja na tomada de posição frente à violência, seja diante dos sentimentos provocados pelo agressor, e pela possibilidade de reconhecimento de seu papel tanto de sustentação do processo de violência conjugal e/ou familiar como de ruptura do mesmo.

Concomitante a isso, confirma-se a repercussão devastadora da violência em termos de saúde física e psicológica, o que deixa a mulher, muitas vezes, subjugada a diagnósticos psicopatologizantes e a tratamentos medicamentosos, e a ter de enfrentar o cotidiano com muito sofrimento, o que lhes exige esforço extra para ter condições de dar continuidade a sua vida. Nesses casos, a possibilidade de a mulher utilizar recursos familiares, sociais, econômicos, entre outros, pode ser o meio mais eficaz e efetivo de ajuda.

Vale ressaltar, ainda, o papel do psicólogo no momento de intervir nessas situações. Para uma maior eficácia da atuação desse profissional, faz-se necessário entender e abordar a violência contra a mulher como um fenômeno multideterminado por fatores relacionais, sociais, culturais, econômicos e históricos e por estigmas de gênero, e que é preciso o debate permanente das questões éticas, da violação e da promoção dos direitos da mulher. Com isso, esses profissionais poderão auxiliar na elaboração de estratégias que gerem a possibilidade de mudança nas condições de enfrentar o referido agravo, com o compromisso de promover a saúde e a cidadania dessas mulheres.

Considera-se, igualmente, relevante aprofundar cada vez mais os estudos sobre as variáveis constitutivas da dinâmica psicológica de mulheres que se submetem a uma relação conjugal e/ou familiar violenta, assim como sobre o papel das redes de suporte social junto a mulheres agredidas, enquanto recursos a serem utilizados em face da violência vivida por elas.

Por fim, acredita-se que os dados deste estudo se somam ao campo do conhecimento existente, para evidenciar e/ou desvendar os indicadores de violência contra mulher e suas formas de enfrentamento, para assim poder confrontar os preconceitos relacionados ao tema, principalmente devido ao desconhecimento e à falta de instrumentalização dos profissionais que lidam com as diferentes facetas ou formas da violência contra a mulher.

\section{Referências}

Alberdi, I. (2005). Cómo reconocer y cómo erradicar la violencia contra las mujeres. In Programa de Prevención de la obra social la Caixa. Violencia: Tolerancia cero (pp. 9-87). Barcelona: Fundación la Caixa.

Antoniazzi, A. S., Dell'Aglio, D. D., \& Bandeira, D. R. (1998). O conceito de coping: Uma revisão teórica [Versão eletrônica]. Estudos de Psicologia, 3(2), 273294. Recuperado em 17 julho 2008, de http://www.scielo. br/pdf/epsic/v3n2/a06v03n2.pdf

Azevedo, M. A. (1985). Mulheres espancadas. A violência denunciada. São Paulo: Cortez.

Bedone, A. J., \& Faúndes, A. (2007). Atendimento integral às mulheres vítimas de violência sexual: Centro de assistência integral à saúde da mulher, Universidade Estadual de Campinas [Versão eletrônica]. Cadernos de Saúde Pública, 23(2), 465-469. Recuperado em 28 julho 2007, de http://www.scielo.br/pdf/csp/v23n2/24.pdf

Biasoli-Alves, Z. M. M. (1998). A pesquisa em psicologia. Análise de método e estratégias na construção de um conhecimento que se pretende científico. In G. Romanelli \& Z. M. M. Biasoli-Alves (Orgs.), Diálogos metodológicos sobre prática de pesquisa (pp. 135-157). Ribeirão Preto, SP: Legis Summa. 
Cantera, L. M. (2007) Casais e violência: Um enfoque além do gênero. Porto Alegre: Dom Quixote.

Carneiro, A., \& Oliveira, S. (2008). Violência intrafamiliar baseada em gênero com implicação de risco de vida: Mulheres abrigadas na Casa Abrigo Maria Haydeé/ Rio Mulher/Rio de Janeiro. Encontro Nacional de Estudos Populacionais, ABEP, 16. Recuperado em 12 dezembro 2008, de http:/www.abep.nepo.unicamp.br/ encontro2008/docsPDF/ABEP2008_1031.pdf

Cavalcanti, L. F., Gomes, R., \& Minayo, M. C. S. (2006). Representações sociais de profissionais de saúde sobre violência sexual contra a mulher: Estudo em três maternidades públicas municipais do Rio de Janeiro, Brasil [Versão eletrônica]. Cadernos de Saúde Pública, 22(1), 31-39. Recuperado em 25 agosto 2007, de http:// www.scielo.br/pdf/csp/v22n1/04.pdf

Ferrari, D. C. A., \& Vecina, T. C. C. (2002). O fim do silêncio na violência familiar. Teoria e prática. São Paulo: Ágora.

Folkman, S., Lazarus, R. S., Gruen, R. J., \& DeLongis, A. (1986). Appraisal, coping, health status, and psychological symptoms. Journal of Personality and Social Psychology, 50(3), 571-579.

Lei No. 11.340, de 7 de agosto de 2006. (2006, 7 de agosto). Cria mecanismos para coibir a violência doméstica e familiar contra a mulher. Constituição da República Federativa do Brasil. Recuperado em 10 outubro 2008, de http://www.planalto.gov.br/ccivil_03/_Ato20042006/2006/Lei/L11340.htm

Ministério da Saúde. (2002). Violência intrafamiliar: Orientações para a prática em serviço. Brasília, DF: Ministério da Saúde. Recuperado em 19 setembro 2008, de http://bvsms.saude.gov.br/bvs/publicacoes/cd05_19. pdf

Moré, C. L. O. O. (2005). As redes sociais significativas como instrumento de intervenção psicológica no contexto comunitário. Paidéia (Ribeirão Preto), 15(31), 267-297.

Muhr, T. (2004). ATLAS/ti the knowledge workbench. V 5.0 Quick tour for beginners (2nd ed.) Berlin: Scientific Software Development.

Peralta, R. L., \& Fleming, M. F. (2003). Screening for intimate partner violence in a primary care setting: The validity of feeling safe at home and prevalence results. The Journal of the American Board of Family Medicine, 16(6), 525-532. Recuperado em 20 outubro 2008, de http://www.jabfm.org/cgi/content/abstract/16/6/525

Santos, C. M., \& Izumino, W. P. (2005). Violência contra as mulheres e violência de gênero: Notas sobre estudos feministas no Brasil. E.I.A.L. Estudios Interdisciplinarios de América Latina y El Caribe, 16. Recuperado em 09 novembro 2008, de http://www.nevusp.org/downloads/ down083.pdf
Schraiber, L. B., D’Oliveira, A. F. P. L., Couto, M. T., Hanada, H., Kiss, L. B., Durand, J. G., Pucia, M. I., \& Andrade, M. C. (2007). Violência contra mulheres entre usuárias de serviços públicos de saúde da Grande São Paulo. Revista de Saúde Pública, 41(3), 359-367. Recuperado em 28 janeiro 2009, de http://www.scielo.br/pdf/rsp/ v41n3/5820.pdf

Silva, L. L., Coelho, E. B. S., \& Caponi, S. N. C. (2007). Violência silenciosa: Violência psicológica como condição da violência física doméstica [Versão eletrônica]. Interface: Comunicação, Saúde, Educação 11(21), 93103. Recuperado em 19 setembro 2008, de http://www. scielo.br/pdf/icse/v11n21/v11n21a09.pdf

Strauss, A. L., \& Corbin, J. (2008). Pesquisa qualitativa. Técnicas e procedimentos para o desenvolvimento de teoria fundamentada (2a ed.). Porto Alegre: Artes Médicas.

Villela, W. V., \& Lago, T. (2007). Conquistas e desafios no atendimento das mulheres que sofreram violência sexual [Versão eletrônica]. Cadernos de Saúde Pública, 23(2), 471-475. Recuperado em 24 julho 2007, de http://www. scielo.br/pdf/csp/v23n2/25.pdf

Wenzel, J. D., Monson, C. L., \& Johnson, S. M. (2004). Domestic violence: Prevalence and detection in a family medicine residency clinic [Versão eletrônica]. The Journal of the American Osteopathic Association, 104(6), 233-239. Recuperado em 19 setembro 2008, de http://www.jaoa.org/cgi/content/full/104/6/233

Ana Cláudia Wendt dos Santos é doutoranda do Programa de Pós-graduação em Psicologia Social do Instituto de Psicologia da Universidade de São Paulo.

Carmen Leontina Ojeda Ocampo Moré é Professora Adjunta IV do Departamento de Psicologia da Universidade Federal de Santa Catarina.
Recebido: 06/05/2009
$1^{a}$ revisão: $21 / 01 / 2010$
$2^{a}$ revisão: 10/04/2010
Aceite final: $04 / 10 / 2010$ 